This item was submitted to Loughborough's Institutional Repository (https://dspace.lboro.ac.uk/) by the author and is made available under the following Creative Commons Licence conditions.

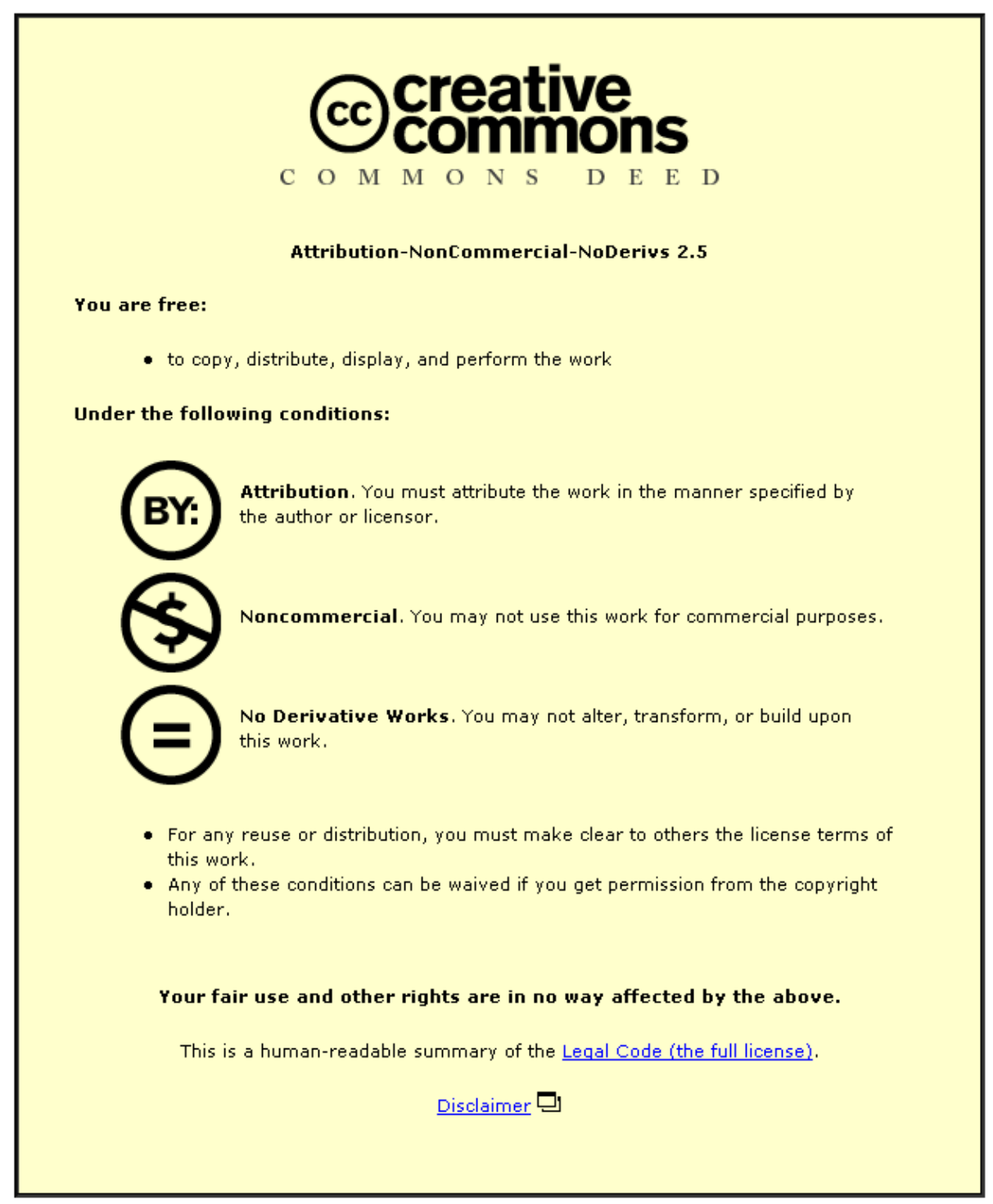

For the full text of this licence, please go to: http://creativecommons.org/licenses/by-nc-nd/2.5/ 


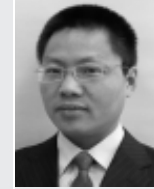

Xin Sun Associate Professor, School of Environmental and Municipal Engineering, $X_{i}$ University of Architecture and Technology, Shaan X PR China

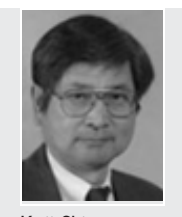

Koji Shiono Professor of Environmental Hydrodynamics, Department of Civil and Building Engineering, Loughborough University,
Loughborough, UK

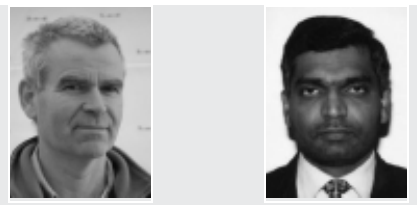

Jim H. Chandler Professor of Geomatics, Department of Civil and Building Engineering, Loughborough University, Loughborough, UK

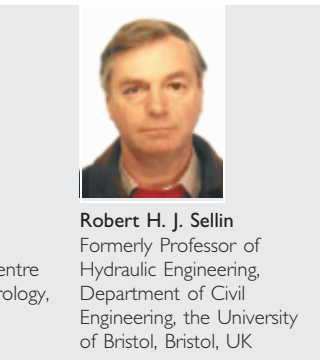

of Bristol, Bristol, UK

\section{Discharge estimation in small irregular river using LSPIV}

X. Sun PhD, K. Shiono PhD, J. H. Chandler PhD, P. Rameshwaran PhD, R. H. J. Sellin PhD and I. Fujita PhD

This paper reports on an estimation method used to quantify discharge in the small irregular channel of the River Blackwater, using large-scale particle image velocimetry (LSPIV). The test reach $(250 \mathrm{~m} \times 60 \mathrm{~m})$ consists of relatively straight and multiple meander channels, with a bankfull depth of $0.90 \mathrm{~m}$ and a base width of $4.25 \mathrm{~m}$. Water surface velocities were measured by LSPIV at three sections along the river. Acoustic Doppler velocimeter (ADV) was also used on two occasions to measure velocity profiles for the validation of water surface velocities of LSPIV. In addition to this field work, velocity data derived from a I:5 physical model of the river were available to compare with the field data. A comparison between the LSPIV data and ADV data was made and agreement was confirmed. The discharge correction factor method was suggested to estimate the discharge in the river. Discharge correction factors of $0.90-1.05$ and I.10-I.I5 were proposed for inbank and overbank flow conditions respectively.

\section{INTRODUCTION}

River discharge is traditionally measured using electromagnetic current meters and acoustic sensor methods in the area where there are no flow measurement devices. These methods require special devices to put the measurement instruments into the river and have some inherent drawbacks of flow disturbance. Moreover, it is very dangerous to use these methods during river floods. Image-based velocity measurement techniques, such as large-scale particle image velocimetry (LSPIV), is a potential alternative and has gained increasing popularity in the river engineering community. Following Fujita's pioneering work (Fujita and Komura, 1994; Fujita et al., 1998), the LSPIV technique has been improved (Fujita and Tsubaki, 2002; Fujita and Aya, 2000) and applied to measure free-surface velocities in large-scale rivers spanning up to $45000 \mathrm{~m}^{2}$ under different velocity ranges (Creutin et al., 2003; Fujita et al., 1998; Meselhe et al., 2004). For example, LSPIV was successfully applied to measure the discharges in the Yodo river (Fujita et al., 1998) with a width (W) of $230 \mathrm{~m}$ and a depth (H) of $8 \mathrm{~m}$, Kino River (Fujita and Aya, 2000) and Uono River (Fujita and Tsubaki, 2002) in Japan, Iowa River (Creutin et al., 2003) $($ W70 $\mathrm{m} \times \mathrm{H6} \mathrm{m})$ in the USA and River Arc (Jodeaua et al., 2008) (W50 m) in France. However, little work has been done in small irregular rivers.
Previous studies of LSPIV focused on the relationship between the surface velocity from LSPIV and depth-averaged velocity. Most researchers introduce a velocity index $k=\left(U_{\mathrm{d}} / U s\right)$, which is the ratio of the depth-averaged velocity $\left(U_{\mathrm{d}}\right)$ to the surface velocity $\left(U_{\mathrm{s}}\right)$. In wide large rivers the flow is thought to be two-dimensional, and the vertical velocity profile follows either the logarithmic law or Prandtl's seventh power law over the water depth (Chanson, 2004). In such a flow case, the theoretical index for the seventh power law is $0 \cdot 875$, which more or less agrees with $k=0.85$ by Creutin et al. (2003) who carried out field measurements using an acoustic Doppler current profiler (ADCP) in the River Iowa.

In small irregular rivers, vertical velocity profiles across a cross-section neither follow the seventh power law nor the logarithmic law, since the flow is three-dimensional. The complex secondary currents also make the velocity index $k$ vary from location to location across cross-sections. Thus the use of a $k$ value of 0.85 might yield inaccurate discharge estimation in such rivers. In order accurately to estimate discharge for small irregular rivers using LSPIV, an easier and more convenient approach to estimate the river discharge using the surface velocity data from LSPIV needs to be explored. The three-year research project entitled 'New approaches to estimating flood flows via surface videography and 2D \& 3D modelling', funded by the UK Engineering and Physical Sciences Research Council (EPSRC), makes it possible to explore the new approach in a small irregular river, namely the River Blackwater, Hampshire, UK.

In the River Blackwater, the water surface velocities and the vertical profiles of velocity were measured using LSPIV and acoustic Doppler velocimeter (ADV) respectively. Free water surfaces were measured using a digital photogrammetry (DP) technique. River discharges were measured using an ADCP technique. In addition to the River Blackwater data, data representing a 1:5 scale physical model were available. This replicate was built in the Flood Channel Facility (FCF) at HR Wallingford, from which the velocities and boundary shear stresses were measured by Lambert and Sellin (1996). The measured data will be used to understand flow behaviour in relevant sections of the River Blackwater since the flow structure was not able to be sufficiently explained using the limited ADV and LSPIV measurement data. This paper also examines the water surface velocity vectors obtained from LSPIV under various conditions of vegetation and furthermore 
compares the measured velocities and the estimated discharges between LSPIV and ADV, addressing difficulties in using LSPIV.

\section{FIELD SITE AND DATA ACQUISITIONS}

\section{I. Field site}

The study reach of the River Blackwater near Farnborough is a two-stage doubly meandering channel, with a valley slope of $1: 1020$. The thalweg slope is $0 \cdot 00085$ with a corresponding sinuosity of 1:18 (Sellin and van Beesten, 2004). The bankfull main channel flow and the two-stage 100-year flood flow were designed to be $1.5 \mathrm{~m}^{3} / \mathrm{s}$ and $4.3 \mathrm{~m}^{3} / \mathrm{s}$ respectively.

Figures 1(a) and 1(b) show the plan views of the study reach of the River Blackwater and its 1:5 scale physical replicate respectively. The designed cross-section of the main channel was trapezoidal, with a bottom width of $4.25 \mathrm{~m}$, a top width of $5.75 \mathrm{~m}$, a depth of $0.75 \mathrm{~m}$ and side slopes of $45^{\circ}$. The measurement sections were selected at the straight section CS2, the cross-over section CS4 and the apex section CS5. Benchmarks and targets necessary for LSPIV and DP were permanently fixed along the measuring sections. Table 1 lists the main channel discharges for six field measurements (five inbank flows and one overbank flow). In this table, the date format is ddmmyy, that is 170107 represents 17 January 2007. In the overbank case 060307, the floodplain was covered by vegetation and the strong reflection of light owing to vegetation made LSPIV results for the floodplain surface flow unsatisfactory, hence LSPIV analysis was only limited to the main channel.

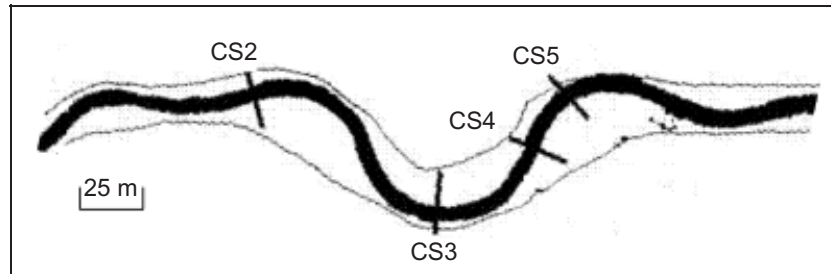

(a)

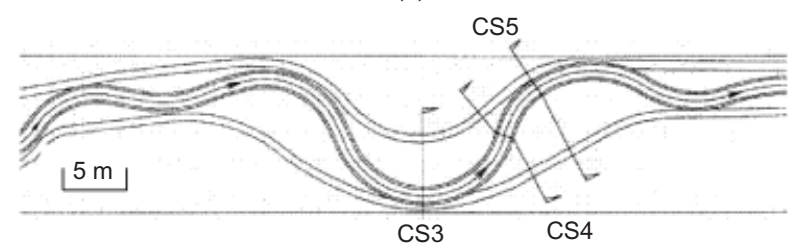

(b)

Figure I. Plan views of River Blackwater and its 1:5 physical model: (a) river; (b) model

\subsection{Bed and water level measurements}

In January 2007, a total of 12 control points were established to provide spatial cover of the study reach. The coordinates of the 12 points were measured using differential global positioning system (GPS) and a Leica total station (TCR1203), and were used to establish the coordinates of the targets of LSPIV and DP. After the annual cutting of vegetation in March 2007, the detailed measurements of the study reach bathymetry were carried out with the Leica motorised total station (TCA1105). The mesh sizes are around $1.5 \mathrm{~m} \times 2.0 \mathrm{~m}$ for the floodplain and $0.5 \mathrm{~m} \times 2.0 \mathrm{~m}$ for the main channel. As a result, the bankfull water depth was $0.90 \mathrm{~m}$, which is $0.15 \mathrm{~m}$ deeper than the original designed bankfull depth in 1993.

Dynamic water surface levels across the test sections were measured using a DP technique (Chandler et al., 2008). A pair of synchronised high-resolution digital cameras (10 megapixel), Nikon D80's were set up at about 4-5 m from the main channel edge of the floodplain, used to capture two synchronised images and successive images were taken at rates of up to three frames per second. DP data were used to determine water elevation across the section. The water levels were also measured from the staff gauges at sections CS2 and CS5. The differences of measured water levels using these two methods were within $\pm 1 \mathrm{~cm}$, which does not influence the LSPIV results. To make field work easier, water levels from the staff gauges were used at CS2 and CS5, but DP was used at CS4. White biodegradable packing chips and sawdust were spread on the water surface to provide appropriate texture for DP and LSPIV measurements.

The measured bed geometries and water levels were used to calculate the local water depths across the sections, from which the depth-averaged velocities and discharges were estimated.

\subsection{LSPIV}

Two components of water surface velocity were measured with an LSPIV technique. LSPIV is an extension of conventional particle image velocimetry (PIV) to measure velocity over a large flow area (Fujita et al., 1998). As with conventional PIV, the core goal of LSPIV is to obtain the displacement of small marked flow regions, or interrogation areas, between two successive images using an image processing approach. The surface velocity vector for each interrogation area is then determined by dividing the displacement by the time interval between measured successive recordings. The whole velocity vector field is obtained by using the image analysis method for each interrogation area in the studied flow area. The final velocity vector field is established by time-averaging all instantaneous velocity vector fields. For the LSPIV technique in

\begin{tabular}{|c|c|c|c|c|c|c|}
\hline & 170107 & 201107 & 061207 & 160108 & 280508 & 060307 \\
\hline CS2 & 1.61 & 1.83 & 0.92 & $2 \cdot 13$ & 1.28 & 3.04 \\
\hline CS4 & 1.57 & 1.80 & 0.91 & $2 \cdot 08$ & 1.25 & $3 \cdot 39$ \\
\hline CS5 & $1.5 \mid$ & 1.73 & 0.87 & 2.00 & 1.20 & 2.92 \\
\hline $\begin{array}{l}\text { Flow } \\
\text { conditions }\end{array}$ & Inbank & Inbank & Inbank & Inbank & $\begin{array}{c}\text { Inbank/ } \\
\text { vegetation }\end{array}$ & Overbank \\
\hline
\end{tabular}


this study, the marker displacements were determined by computing the two-dimensional cross-correlation between the interrogation area in the first image and the same interrogation area in the second image. The location of the highest crosscorrelation statistic is being used for displacement estimation. The spatial resolution of the measurement is determined by the size of the interrogation area, set to $0.20 \mathrm{~m}$ in this study.

In the field study, two fully mobile video cameras were used for the LSPIV capable of being deployed within a few minutes. A high-resolution camcorder camera (Sony DCR-TRV22 High8 Handycam) with remote control was mounted on an adjustable-height mast, with the tripod on the floodplain. The viewing angle of the camera could be adjusted by rotating the camera horizontally and vertically using a remote control. A hard disk digital camcorder (JVC Everio GZ-MG275) was also used, which was fixed on a ladder. This was able easily to move to any location in the test reach. It was found necessary to adjust the viewing angle, to avoid a strong reflection of light owing to the riverbank, vegetation and trees. In vegetated and shallow slow flow cases, sawdust and the biodegradable packing clips were used as seeding agents on the water surface, to provide discrete features necessary to correlate. Based on the accurate coordinates of the targets on the floodplain, the inclined video image was orthogonally rectified to an appropriate horizontal datum and subsequent surface velocity vectors were obtained in a real-world coordinate system using the LSPIV software (Fujita et al., 1998).

At each measurement section, a 2 min video recording was acquired. The time-averaged mean velocities were calculated by selecting good images over $30 \mathrm{~s}$ and longer if natural and manual seedings were insufficient. To remove noise within the velocity data, the probability density distribution of instantaneous $u$ over the recorded time was established first, then data within a 95\% confidence limit were accepted and those beyond the 95\% confidence limit were ignored.

In addition to LSPIV, an ADV (Nortek $10 \mathrm{MHz}$ Velocimeter) was also used to measure three components of velocity on the floodplain and in the main channel for shallow water depths. The sample rate and the recorded time of ADV were $25 \mathrm{~Hz}$ and $300 \mathrm{~s}$ respectively. The data were then compared with the LSPIV results. The result will be discussed in Section 3.

\section{LSPIV TESTS}

There were difficulties in using an LSPIV technique in the River Blackwater, which were from the reflection of light, angle of camera and scattered seedings. In many natural rivers, distinctive images texture is created by large-scale turbulence eddies, surface waves, floating objects, debris on the water surface. However, sufficient texture contrast might not be available owing to a strong reflection of light due to marginal vegetation, clouds, river banks and a mirror-like calm water surface. In such cases, seeding is required for LSPIV to measure water surface velocity reliably, and to spread in 10-30\% of the measuring surface area as suggested by Meselhe et al. (2004).

As LSPIV uses an image-based technique, the image quality is vitally important. In natural rivers, an inherent image distortion is associated with the oblique viewing angle of a video camera. Fujita and Aya (2000) refined the standard image transformation procedure DLT in the LSPIV software to improve the correction of the image distortion. Under the oblique angle condition, the accuracy of distance estimation can be improved from 23\% in the original LSPIV to 3\% in the refined LSPIV (Fujita and Aya, 2000). The error of 3\% is comparable with the discharge error. This software was used in this study. The angle of the camera was set to $20^{\circ}$ for avoiding the strong reflection of light, with sawdust and biodegradable packing chips spreading in more than 30\% of the measurement surface areas used as a seeding agent.

The LSPIV results were first compared with velocities measured by ADV. ADV measurements were carried out to measure vertical velocity profiles at four lateral locations in CS5 on 17/01/07 and one lateral location in CS2 on 23/06/07, and also velocities at $6 \mathrm{~cm}$ below the water surface at three lateral locations in CS2 on 23/06/07. In the ADV measurements, the vertical interval at each lateral location was $H / 10$, where $H$ is the local water depth $(\mathrm{m})$. Figure 2 shows the comparison between ADV and LSPIV data at those points. The surface velocities measured with LSPIV agreed reasonably well with those of ADV. A further example in Figure 3 shows one detailed vertical velocity profile at $Y=4.72 \mathrm{~m}$ of CS2, one of the measurement locations. It can be seen from the figure that the surface velocity from LSPIV coincides well with the surface velocity obtained by an extension of the vertical velocity profile from ADV. This confirms that velocities of water surface can be reasonably well estimated with LSPIV. The secondary vectors at CS5 in the River Blackwater were also plotted on Figure 4(a), which exhibits a clear secondary flow. As shown in Figure 4(b) after Naish and Sellin (1996), the lateral velocity pattern at CS5 of the physical model case B132 is similar to the secondary flow pattern at CS5 in the River Blackwater. The River Blackwater well reproduced the flow structure in the

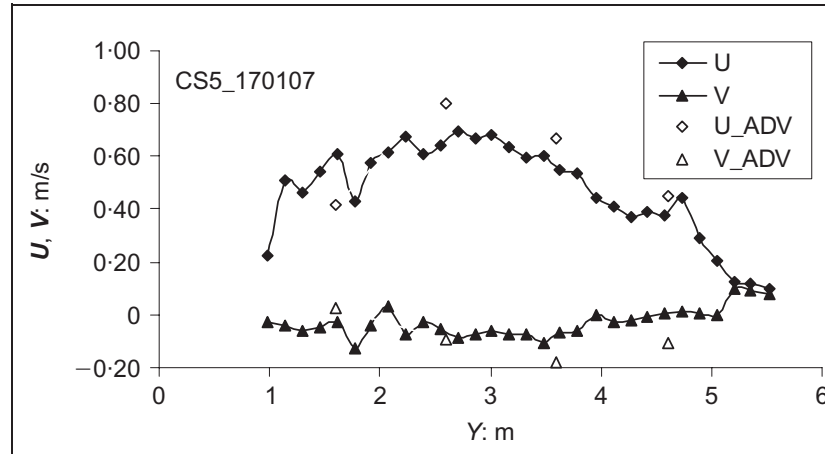

(a)

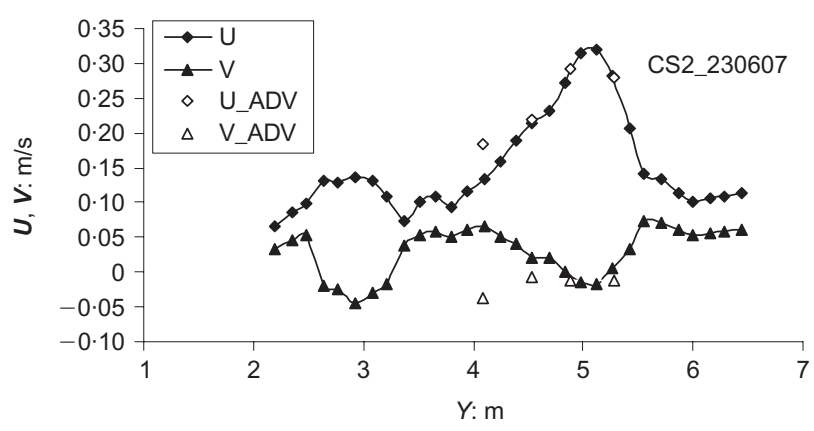

(b)

Figure 2. Lateral distributions of surface velocities from LSPIV and local velocities at $5 \mathrm{~cm}$ below the water surface from ADV: (a) CS5; (b) CS2 


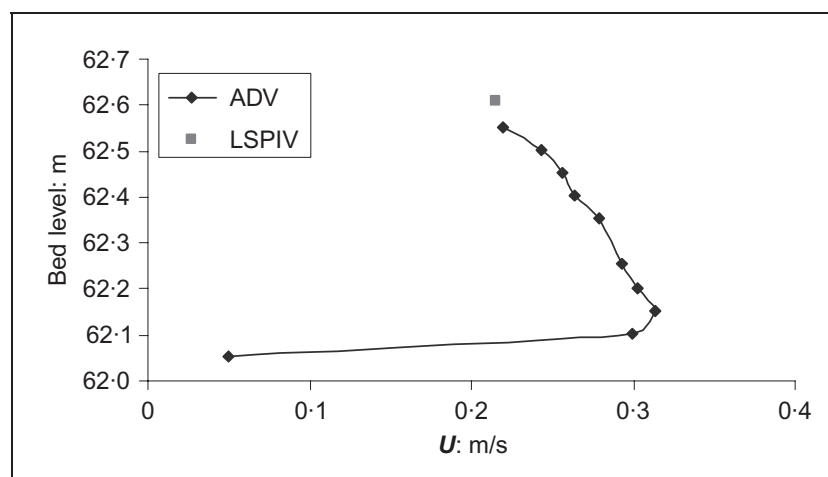

Figure 3. Vertical profiles of the streamwise velocity at $Y=4.72 m$ of section CS2 (23 June 2007)

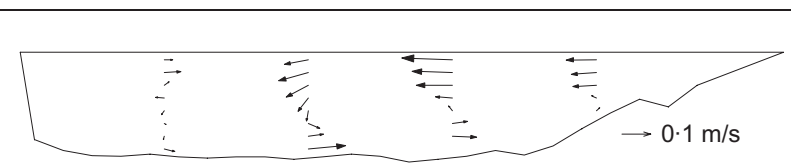

(a)

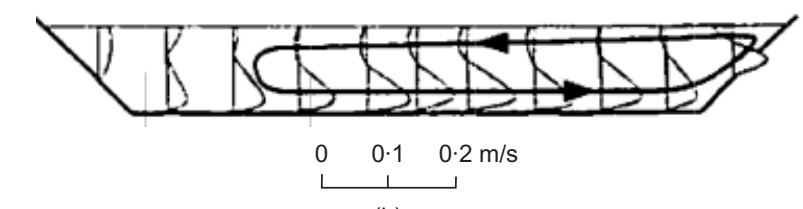

(b)

Figure 4. Measured secondary flows with ADV at CS5 in the River Blackwater: (a) river case 170107; (b) model case B| 32

physical model, and the flow in this section is threedimensional, therefore a standard approach of LSPIV for an estimation of discharge may not work.

\section{DISCHARGE ESTIMATION ON THE RIVER BLACKWATER}

\section{I. Velocity distributions across the sections}

The LSPIV measured surface velocities at the three sections, including the five inbank cases and one overbank case are listed in Table 1. Figure 5 shows the lateral distributions of the projected streamwise velocity and the bed geometry at the straight section CS2. WL represents water level at the section and the direction of the lateral coordinate system starts from the left top main channel when looking downstream. As can be seen from the dates, the data include summer and winter seasons. It was observed that in the winter months there was less vegetation in the main channel and on the floodplain, but was heavily vegetated in the summer months (see Figures 6 and 7). It can be seen from Figure 5 that, for the inbank flow case, the surface velocities increase with the water levels for the winter month cases as expected from an open channel flow concept, but not for the summer case (280508) as they are dependent on vegetation condition.

For inbank flow, the velocity distributions between winter and summer cases behave differently. The surface velocities were higher towards the right of the main channel in the winter months, which is similar to those in the physical model (shown in a later section). During the summer months when vegetation

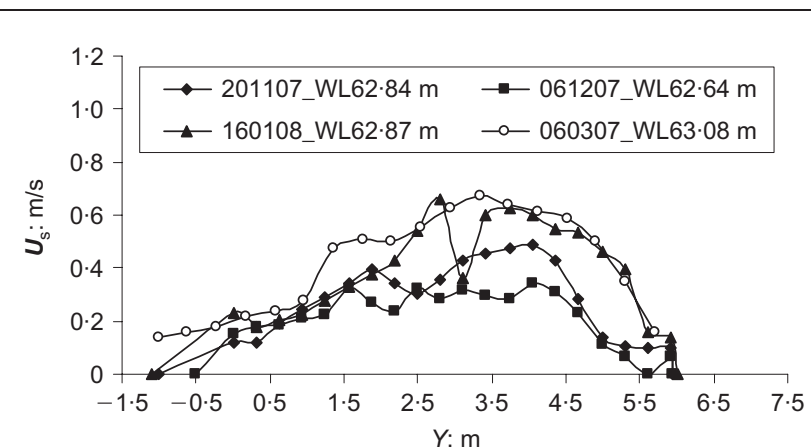

(a)

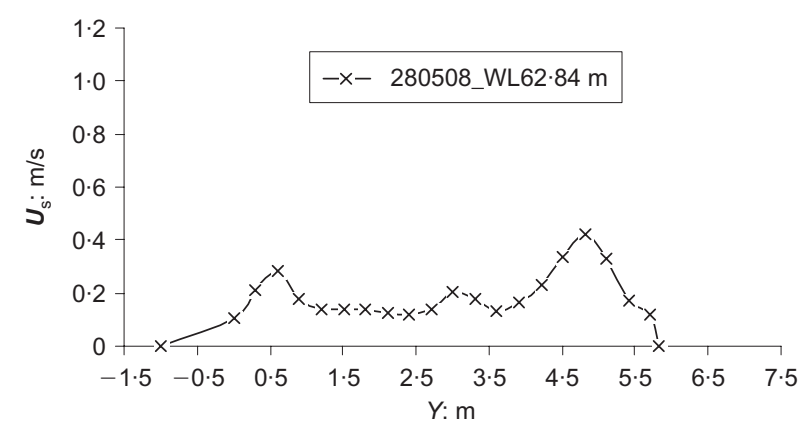

(b)

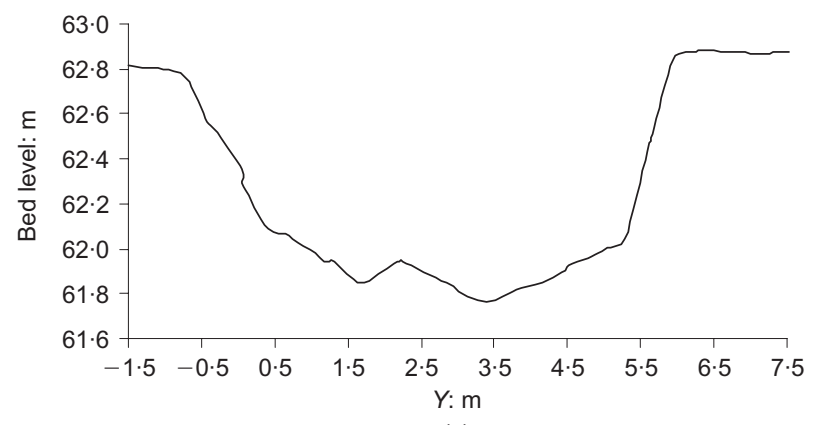

(c)

Figure 5. Lateral distributions of the streamwise velocity and the river bed at straight section CS2: (a) winter; (b) summer; (c) bed

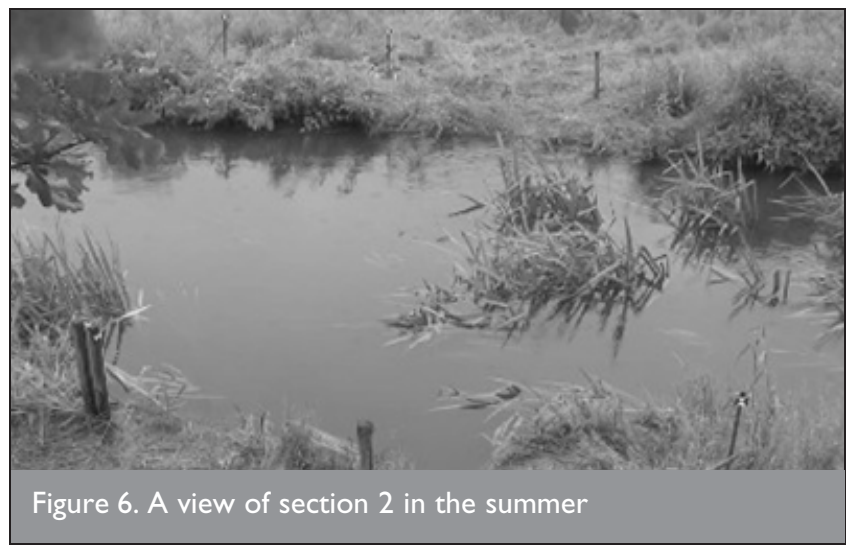

covered from the mid-channel to the left bank in CS2 upstream, the surface velocities peak towards the right bank. This is due to the flow contraction between the left bank and vegetation upstream. The surface velocities behind the vegetation were relatively lower owing to a wake effect (Nezu et al., 2006).

For the overbank flow case 060307 and inbank flow case 


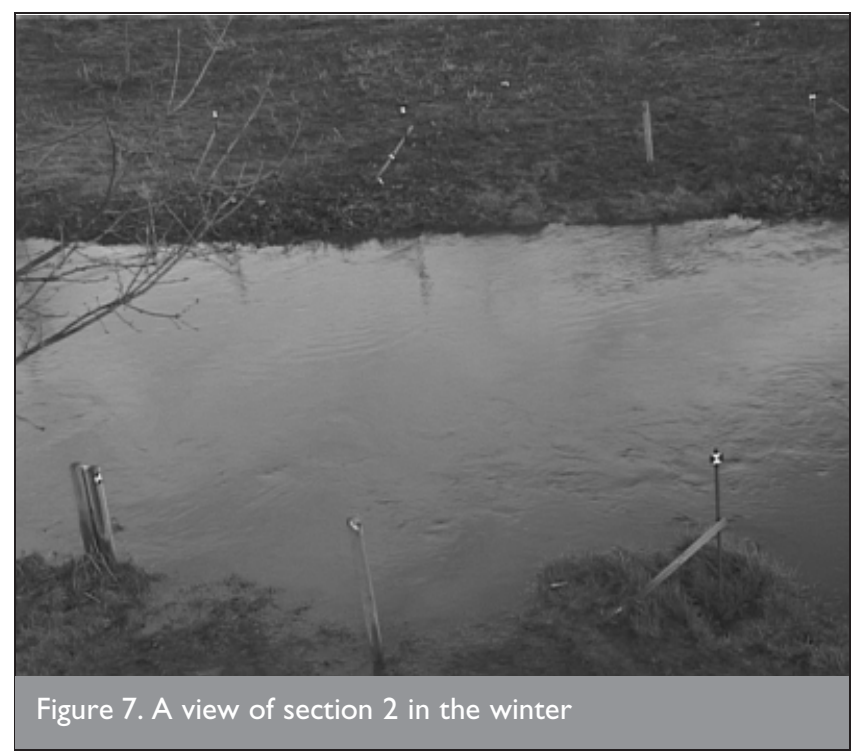

280508 , at the cross-over section, CS4, the surface velocities shown in Figure 8 peak towards the right side of the main channel. The physical model will show a later section that the surface velocity is much larger for inbank flow than for

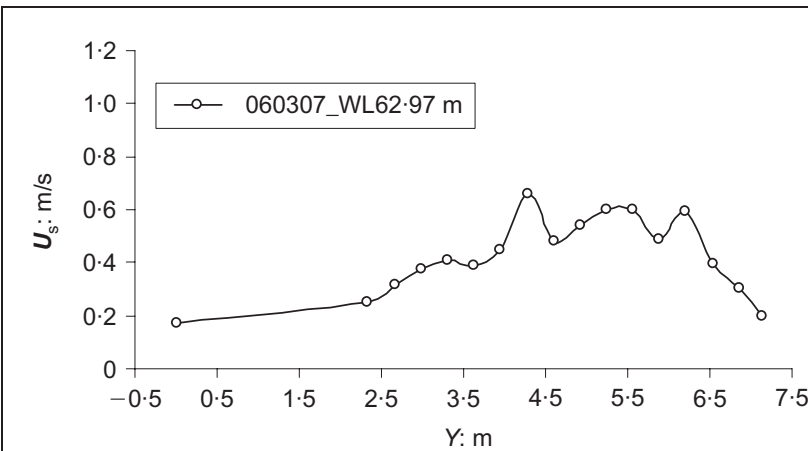

(a)

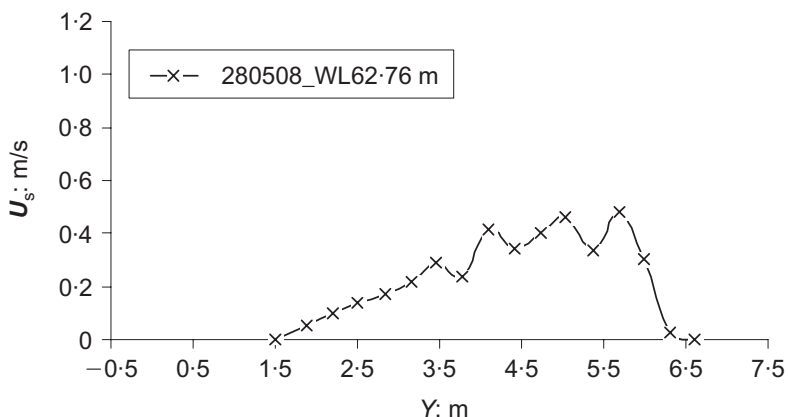

(b)

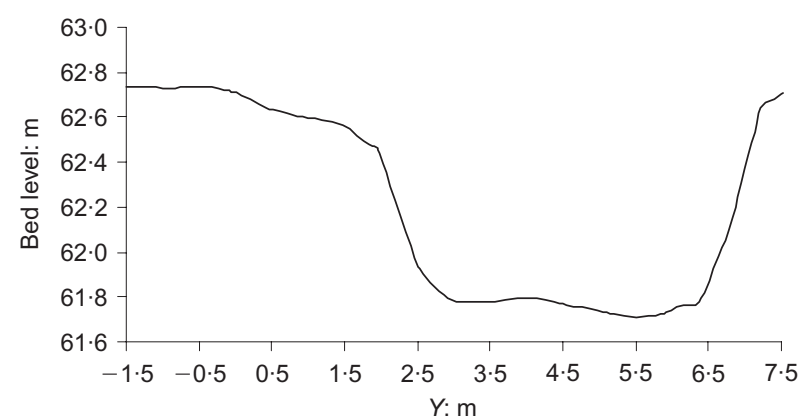

(c)

Figure 8. Lateral distributions of the streamwise velocity of the river bed at straight section CS4: (a) winter; (b) summer; (c) bed overbank flow; however, this figure shows the opposite. As mentioned before that vegetation on 280508 was heavy in the main channel, thus the vegetation on the main channel bed causes a substantial reduction in the surface velocities due to the vegetal drag force.

At the apex section CS5, Figure 9 shows a peak velocity towards the right side of the main channel (inner side) and their magnitudes increase as the water levels increase except for the 060307 flood case. In the heavy vegetation case, the velocities were significantly lower than in the winter bankfull case (160108). Again this is showing the vegetation effect.

The above demonstrates that flow patterns that occur in the River Blackwater in winter months are very similar to those in the physical model whereas the flow pattern in the summer months differs significantly. This is undoubtedly due to vegetation. The distribution of vegetation in the main channel influences the flow structure to be formed in three-dimensional nature, which implies that the velocity index in LSPIV used widely is not 0.87 as the flow is not two-dimensional. This leads to the need to investigate the velocity index for such three-dimensional flow cases.

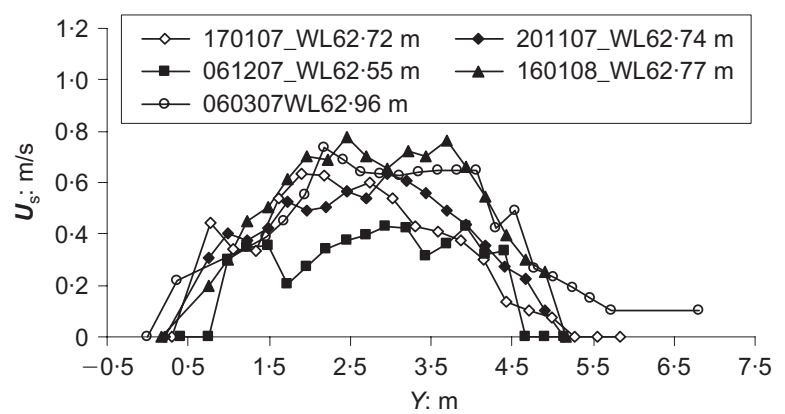

(a)

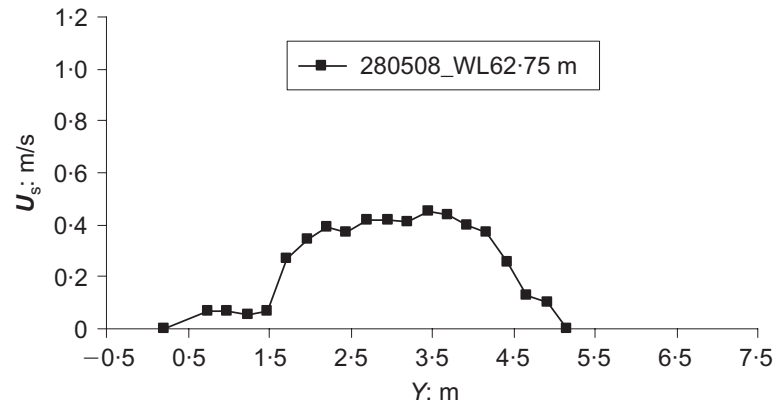

(b)

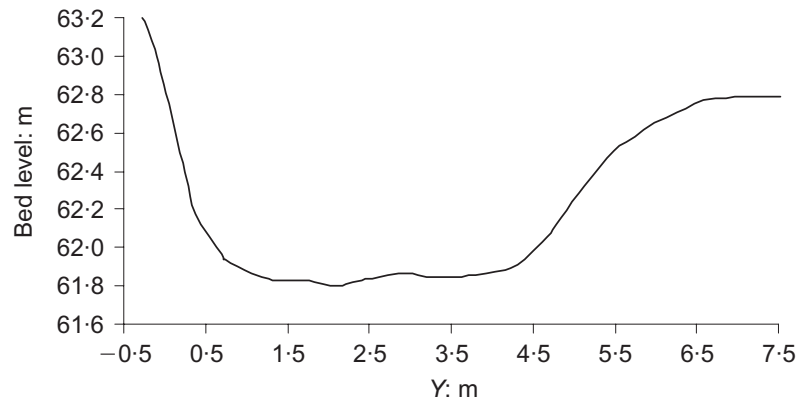

(c)

Figure 9. Lateral distributions of the streamwise velocity and the river bed at bend section CS5: (a) winter; (b) summer; (c) bed 


\subsection{Velocity index method}

In the velocity index method, the main channel discharge $\left(\boldsymbol{Q}_{\mathrm{md}}\right)$ is obtained by integrating $U_{\mathrm{d}} \mathrm{H}$ across the main channel section, where $\boldsymbol{U}_{\mathrm{d}}$ and $H$ are the depth-averaged velocity and water depth respectively. As the flow characteristics in the River Blackwater are similar to those in the 1:5 physical model, an attempt was made to determine $\boldsymbol{U}_{\mathrm{d}}$ with $\boldsymbol{U}_{\mathrm{s}}$ data from LSPIV in the river using the results of the velocity index $k$ from the model experiments. Eight model experiment cases were selected in this study. Table 2 lists the channel and flow conditions. Further experiment details can be found in Lambert and Sellin (1996). Inbank case B132 and overbank case C187 were chosen as the representative inbank and overbank cases in the River Blackwater. Case C187 is the same roughness in the main channel and on the floodplain and similar relative water depth to the one overbank case in the River Blackwater.

Having seen that the flow is three-dimensional at the crossover section CS4 and the apex section CS5 in the River Blackwater, the velocity difference between surface and depthaveraged values is first investigated to identify any local threedimensionality that existed across the section. Figures 10(a) and 10(b) show the cross-sectional distributions of $\boldsymbol{U}_{\mathrm{d}}$ and $\boldsymbol{U}_{\mathrm{s}}$ at sections CS4 and CS5 of the physical model respectively. The origin of the lateral coordinate system starts from the left upper floodplain edge when looking downstream. The velocities at the water surface and the channel bed were interpolated from the measured velocity profile over the depth and then the depth-averaged velocities were calculated. For the inbank case B132, at the cross-over section CS4 (see Figure 10(a)), $U_{\mathrm{d}}$ and $U_{\mathrm{s}}$ peak closer to the outer edge of the channel, around $Y=1.00 \mathrm{~m}$, whereas at the apex section CS5, $\boldsymbol{U}_{\mathrm{d}}$ and $U_{\mathrm{s}}$ peak on the inner side of the bend. The behaviour and magnitude of both velocities are almost identically decreasing towards the left side of the bank.

For the overbank case C187, $\boldsymbol{U}_{\mathrm{d}}$ and $\boldsymbol{U}_{\mathrm{s}}$ still peak on the right side at CS4 and CS5, similar to the inbank case, but with smaller magnitudes. There is a noticeable difference between them near the left side bank at CS4. This is attributable to the interaction/mixing caused by the slower floodplain flow entering the main channel. Figures 11(a) and 11(b) further show the cross-sectional distributions of velocity index $k$. It is clear that the local velocity indices are different to 0.85 for two-dimensional flow, as expected from three-dimensional flow at CS4 and CS5.

Applying these relationships shown in Figure 11 to the River

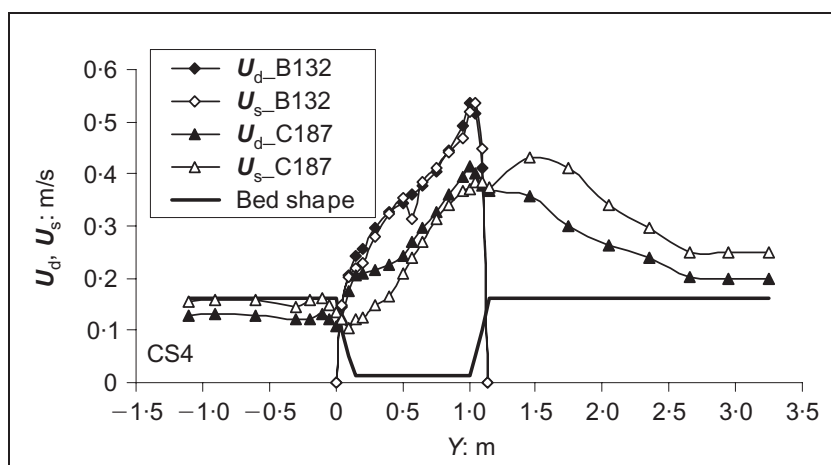

(a)

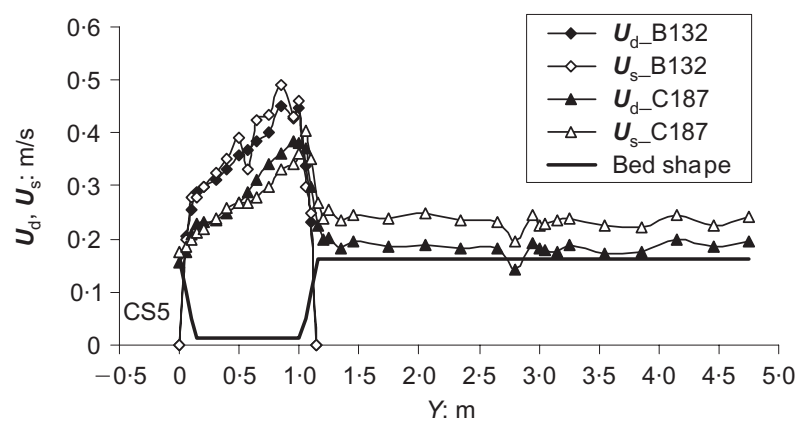

(b)

Figure 10. Lateral distributions of depth-averaged and surface velocities for inbank case $B$ of $H=0.132 \mathrm{~m}$ and overbank case $\mathrm{C}$ of $H=0.187 \mathrm{~m}$ : (a) section 4 ; (b) section 5

Blackwater data obtained from LSPIV at CS4 and CS5 to estimate discharges, the errors between the estimated and measured discharges on the River Blackwater were within - 5\% to $7 \%$, for the both cross-over sections in the winter months. This indicates that discharges in a river can be estimated from LSPIV data using relationships between $\boldsymbol{U}_{\mathrm{d}}$ and $\boldsymbol{U}_{\mathrm{s}}$ in the physical model similar to the river. However, the velocity index $k$ varies across the river section and its relationship at the cross-section is not known in advance if there are no physical model data available, which is the big problem in use of LSPIV data.

\subsection{Discharge correction factor method}

This section introduces a new alternative method to estimate discharge using LSPIV data, which is a discharge correction method. The discharge correction factor method is first to work out the discharge, $\boldsymbol{Q}_{\mathrm{ms}}$, by integration of $\boldsymbol{U}_{\mathrm{s}} H$ across the main channel section and then correcting the discharge with a discharge correction factor $C_{\mathrm{rm}}$ for the main channel, defined

\begin{tabular}{|c|c|c|c|c|c|c|c|c|}
\hline & $\mathrm{B} 132$ & $\mathrm{~B} 187$ & $\mathrm{Cl} 62$ & $\mathrm{Cl} 87$ & $\mathrm{C} 237$ & FI62 & FI87 & F237 \\
\hline Discharge: $\mathrm{m}^{3} / \mathrm{s}$ & 0.043 & 0.125 & 0.063 & 0.084 & 0.175 & 0.062 & 0.082 & 0.165 \\
\hline $\begin{array}{l}\text { Main channel } \\
\text { depth: } H\end{array}$ & 0.132 & 0.187 & 0.162 & 0.187 & 0.237 & 0.162 & $0 \cdot 187$ & 0.237 \\
\hline Floodplain & \multirow{4}{*}{\multicolumn{2}{|c|}{$\begin{array}{l}\text { Horizontal } \\
\text { Size } 8 \mathrm{~mm} \text {, } \\
\text { Depth } 13 \mathrm{~mm} \\
\text { Smooth }\end{array}$}} & \multirow{4}{*}{\multicolumn{2}{|c|}{$\begin{array}{l}\text { Horizontal } \\
\text { Size } 8 \mathrm{~mm} \text {, } \\
\text { Depth } 13 \mathrm{~mm} \\
\text { Size } 8 \mathrm{~mm} \text {, } \\
\text { Depth } 12 \mathrm{~mm}\end{array}$}} & & \multirow{4}{*}{\multicolumn{2}{|c|}{$\begin{array}{l}\text { Horizontal } \\
\text { Size } 8 \mathrm{~mm} \text {, } \\
\text { Depth } 13 \mathrm{~mm} \\
\text { Size } 13 \mathrm{~mm} \text {, } \\
\text { Depth } 16 \mathrm{~mm}\end{array}$}} & \\
\hline Main channel & & & & & & & & \\
\hline roughness & & & & & & & & \\
\hline $\begin{array}{l}\text { Floodplain } \\
\text { roughness }\end{array}$ & & & & & & & & \\
\hline
\end{tabular}




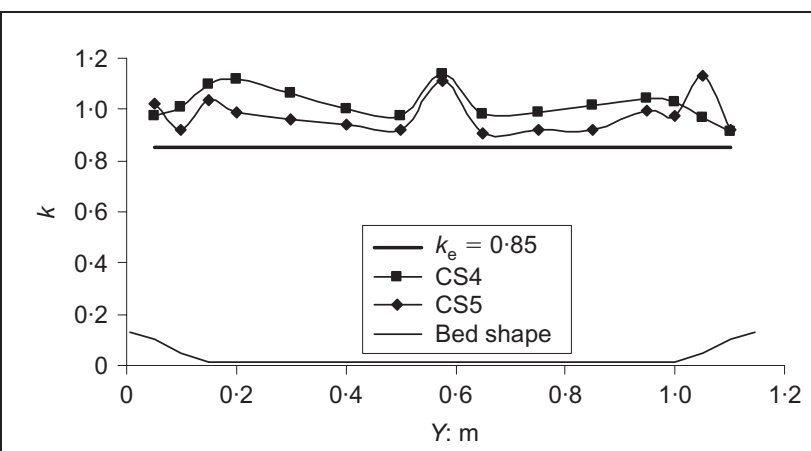

(a)

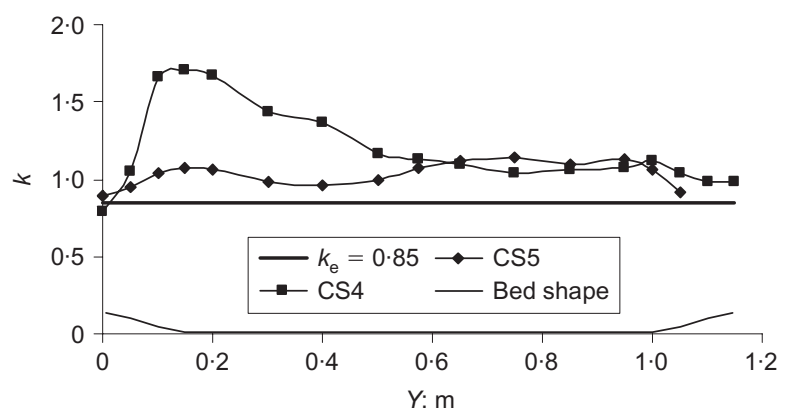

(b)

Figure II. Distributions of velocity index $k\left(=U_{d} / U_{s}\right)$ for inbank case BI 32 and overbank case CI87: (a) case BI32; (b) case $\mathrm{Cl} 87$

as $\boldsymbol{Q}_{\mathrm{m}} / \boldsymbol{Q}_{\mathrm{ms}}$, where $\boldsymbol{Q}_{\mathrm{m}}$ is the measured discharge from ADCP (Gunawan et al., 2008). The discharge correction factors were evaluated using discharge data derived using ADCP. The discharges worked out from ADCP was initially checked with those measured by flow gauges in similar water depths and the error was within \pm 5\% (Gunawan et al., 2009).

Figure 12 shows the discharge correction factors at three sections. In some extremely difficult cases, such as due to the strong reflection of light, surface velocities were not able to be measured correctly using the LSPIV technique, hence correction factors for all the dates were not shown for all three sections. For the inbank flow cases, $C_{\mathrm{rm}}$ is within roughly 0.85-0.90 at CS2 in the winter months similar to two-

dimensional flow, 1.05 in the summer months, except on 20 November 2007, 1.03 at CS4 in May and 1.04 at CS5 in the winter months except on 16 January 2008. For overbank flow, $C_{\mathrm{rm}}$ is between 1.10 and 1.15 at all the measurement sections, CS2, CS4 and CS5.

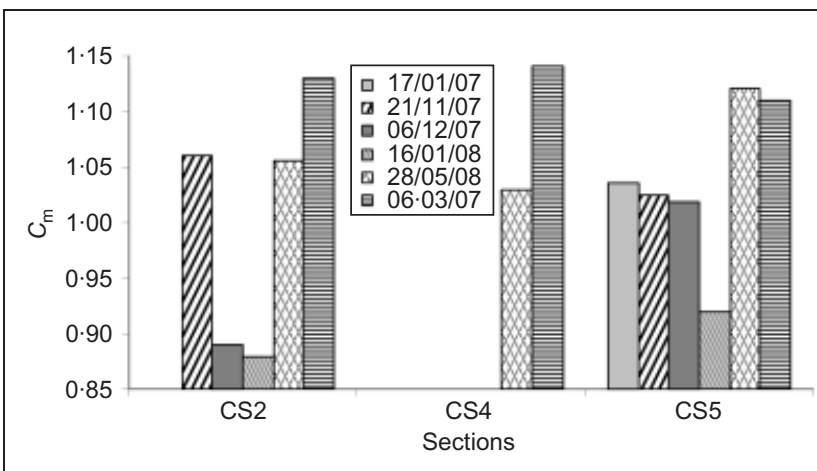

Figure 12. Discharge correction factors for straight and bend sections of the River Blackwater
Applying the discharge correction method to the physical model cases, the discharge correction factor $C_{\mathrm{rm}}$ for the main channel was also calculated and plotted against $\boldsymbol{Q}_{\mathrm{mo}} / \boldsymbol{Q}_{\mathrm{t}}$ in Figure 13, where $\boldsymbol{Q}_{\mathrm{m} 0}$ is the main channel discharge measured using miniature propeller current meters and $Q_{\mathrm{t}}$ is the total discharge measured by a manometer. The figure shows that for inbank flows, $C_{\mathrm{rm}}$ is 1.03 at the cross-over section CS4 and 0.96 the apex section CS5. This indicates that the use of $C_{\mathrm{rm}}=1.0$ gives $\pm 6 \%$ deviation at the measured discharge. For overbank flows, as $\boldsymbol{Q}_{\mathrm{m} 0} / \boldsymbol{Q}_{\mathrm{t}}$ decreases $C_{\mathrm{rm}}$ more or less linearly increases at CS4. Whereas at CS5, $C_{\mathrm{rm}}$ is nearly constant at around $1 \cdot 05$, regardless of the roughness on the floodplain, the relative water depth, or the ratio of discharge $\boldsymbol{Q}_{\mathrm{m} 0} / \boldsymbol{Q}_{\mathrm{t}}$. As a result $C_{\mathrm{rm}}=1.0$ gives $\pm 5 \%$ deviation at the measured discharge.

For overbank flow and with aid of the physical model data, it can be said that the discharge is estimated within 5\% error when LSPIV data with $C_{\mathrm{rm}}=1 \cdot 10$ are used. However, it is noted that more data for overbank flows are required to confirm this relationship.

Compared with the velocity index method, the discharge correction factor method is much simpler and more convenient to use in engineering practice.

\section{CONCLUSIONS}

LSPIV was used to estimate flow rates in a small irregular reach of the River Blackwater over a period of 18 months. From these field measurements combined with earlier laboratory work, the following conclusions were drawn.

(a) The LSPIV results were compared with those measured by

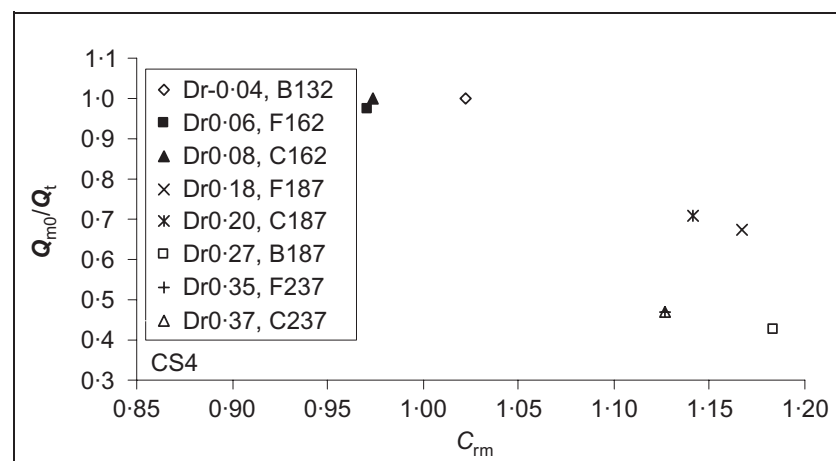

(a)

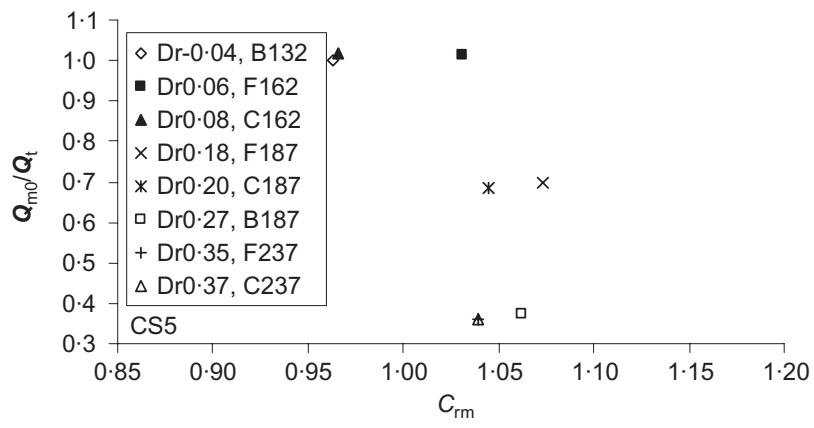

(b)

Figure 13. Relationships between $C_{r m}$ and $Q_{m 0} / Q_{t}$ under different relative water depth conditions: (a) section 4 ; (b) section 5 
$\mathrm{ADV}$, and the surface velocities agreed reasonably well. This confirms that the surface velocities were measured correctly using the LSPIV technique. Based on the ADV measurements at the apex section, the flow structures in the River Blackwater reproduced the physical model ones satisfactorily. Applying the index $k$ relationships between $\boldsymbol{U}_{\mathrm{d}}$ and $\boldsymbol{U}_{\mathrm{s}}$ obtained from the physical model to the River Blackwater, the discharges in the River Blackwater were well predicted with the surface velocity data obtained by LSPIV. The errors between the estimated and measured discharges were within $-5 \%$ to $7 \%$.

(b) For the inbank flow cases, discharge correction factor $\left(C_{\mathrm{rm}}\right)$ for the main channel is within roughly $0 \cdot 85-0.90$ at CS2 in the winter case which is almost the same value for twodimensional flow, 1.05 in the summer case, 1.1 for most inbank flow cases, 1.03 at CS4 in the May case and 1.04 at CS5 in the winter case. Thus different values of $C_{\mathrm{rm}}$ are necessary for winter and summer. For the overbank flow cases, $C_{\mathrm{rm}}$ is between 1.1 and 1.15 at the measurement sections CS2, CS4 and CS5. From only one set of field observations for overbank flow, the discharge was estimated within 5\% error when using LSPIV data and $C_{\mathrm{rm}}=1 \cdot 10$. More data for overbank flows are required to confirm this relationship.

(c) Compared with the velocity index method, the discharge correction method is much simpler and more convenient to use in engineering practice. The correction factor is almost constant for inbank and overbank flows at the apex section; it is therefore recommended to use LSPIV at the apex section CS5 for a better estimation of discharge in the River Blackwater.

\section{ACKNOWLEDGEMENT}

This research is supported by the Engineering and Physical Sciences Research Council grant EP/E003915/1.

\section{REFERENCES}

Chandler H, Wackrow R, Sun X, Shiono K and Rameshwaran P (2008) Measuring a dynamic and flooding river surface by close range digital photogrammetry. Proceedings of the 21 st Congress of the International Society for Photogrammetry and Remote Sensing, Beijing B8, 211-216.

Chanson H (2004) The Hydraulics of Open Channel Flow: An Introduction, 2nd edn. Butterworth-Heinemann, Oxford.

Creutin JD, Muste M, Bradley AA, Kim SC and Kruger A (2003) River gauging using PIV technique: proof of concept experiment on the Iowa River. Journal of Hydrology 277 (3-4), $182-194$.

Fujita I and Aya S (2000) Refinement of LSPIV technique for monitoring river surface flows. Proceedings of a Joint Conference on Water Resource Engineering and Water Resources Planning and Management, Minneapolis, Minnesota, USA.

Fujita I and Komura S (1994) Application of video image analysis for measurements of river-surface flows. Proceedings in Hydraulic Engineering, JSCE 38: $733-738$ (in Japanese).

Fujita I and Tsubaki R (2002) A novel free-surface velocity measurement method using spatio-temporal images. Proceedings of Hydraulic Measurements and Experimental Methods, ASCE-IAHR Conference, Estes Park, CO, USA.

Fujita I, Muste M and Kruger A (1998) Large-scale particle image velocimetry for flow analysis in hydraulic engineering applications. Journal of Hydraulic Research 36(3): 397-414.

Gunawan B, Sterling M and Knight DW (2009) A short note on using an acoustic Doppler current profiler in a small river. Water and Environmental Journal, CIWEM doi: 10.1111/ j.1747-6593.2009.00168.x (in press).

Gunawan B, Sun X, Sterling M et al. (2008) An integrated and novel approach to estimate the conveyance capacity of the River Blackwater. Proceedings of the 8th International Conference on Hydro-Science and Engineering, Nagoya VIII, 221.

Jodeaua M, Hauetb A, Paquiera A, Coza J Le and Dramaisa G (2008) Application and evaluation of LS-PIV technique for the monitoring of river surface velocities in high flow conditions. Flow Measurement and Instrumentation 19(2): $117-127$.

Lambert MF and Sellin RHJ (1996) Velocity distribution in a large-scale model of a doubly meandering compound channel. Proceedings of the Institution of Civil Engineers, Water Maritime and Energy 118(1): 10-20.

Meselhe EA, Peeva T and Muste M (2004) Large scale particle image velocimetry for low velocity and shallow water flows. Journal of Hydraulic Engineering, ASCE 130(9): 937-940.

Naish C and Sellin RHJ (1996) Flow structures in a large scale model of a doubly meandering compound river channel. In Coherent Flow Structures in Open Channels (Ashworth PJ, Bennett SJ, Best JL and McLelland SJ (eds)). Wiley, Chichester, pp. 631-654.

Nezu I, Sanjou M and Okamoto T (2006) Turbulence structure and dispersive properties in vegetated canopy open-channel flows. Proceedings of River Flow 2006, International Conference on Fluvial Hydraulics, Lisbon 583-592.

Sellin RHJ and van Beesten DP (2004) Conveyance of a managed vegetated two-stage river channel. Proceedings of the Institution of Civil Engineers, Water Management 157(1): 21-33.

\section{What do you think?}

To discuss this paper, please email up to 500 words to the editor at journals@ice.org.uk. Your contribution will be forwarded to the author(s) for a reply and, if considered appropriate by the editorial panel, will be published as discussion in a future issue of the journal.

Proceedings journals rely entirely on contributions sent in by civil engineering professionals, academics and students. Papers should be 2000-5000 words long (briefing papers should be 1000-2000 words long), with adequate illustrations and references. You can submit your paper online via www.icevirtuallibrary.com/content/journals, where you will also find detailed author guidelines. 